\title{
25-Hydroxyvitamin D2 and 25- Hydroxyvitamin D3 Measurement
}

National Cancer Institute

\section{Source}

National Cancer Institute. 25-Hydroxyvitamin D2 and 25-Hydroxyvitamin D3

Measurement. NCI Thesaurus. Code C147446.

The determination of the amount of 25-hydroxyvitamin D2 and 25-hydroxyvitamin D3 present in a sample. 